\title{
Formation and Properties of Aqueous Compatible Colloidal Blends between Pre- gelatinized Maize Starch and Zein
}

Welday H. Teklehaimanot, John. R. N. Taylor and Mohammed N. Emmambux*

Department of Food Science, University of Pretoria, Hatfield 0028, South Africa

This study investigates the formation and properties of compatible binary colloidal blends between pre-gelatinized (uncomplexed and complexed with stearic acid) maize starches (hydrophilic component) and commercial zein (hydrophobic component) with the aim of creating a bipolymeric material with unique properties. The blends were formed under alkaline condition (0.1 M NaOH) with 3:1, 1:1 and 1:3 starch: zein (w/w) ratios. The 3:1 starch-zein blends showed best stability or compatibility. Blends made with starch complexed with stearic acid had better stability than those with uncomplexed starch. Most of the blends were not freezethaw stable except for 3:1 starch (complexed with stearic acid)-zein blend. The blends with better stability had higher apparent viscosity, and a microstructure showing uniform mix of starch - zein as observed by confocal laser scanning microscopy. The likely reason for the compatibility of starch and zein is the change in surface activity of zein, possibly due to deamidation, in $0.1 \mathrm{M} \mathrm{NaOH}$ as shown by the negative zeta potential values. The pre-gelatinized maize starches also show negative zeta potential values. In conclusion, compatible binary colloidal blends can be produced between pre-gelatinized maize starch and commercial zein using $0.1 \mathrm{M} \mathrm{NaOH}$.

Key Words: colloidal blends; biocompatible; surface activity

*Corresponding Author: Department of Food Science, University of Pretoria, Hatfield 0028, South Africa, Tel: +27 124202059 Fax: +27 124202839 E-mail: naushad.emmambux@up.ac.za 


\section{INTRODUCTION}

The biopolymers starch and zein (maize prolamin protein) have many food and non-food biomaterial applications. Biomaterial application of starch due to its unique physicochemical and functional properties include: carrier for active materials (Kaur et al., 2007 and as biodegradable films (Weber et al., 2002). Zein can also be used for encapsulation to achieve controlled release of drugs (Mathiowitz et al., 1991), as coatings for cosmetic products (Avalle, 1998) and as biodegradable films and plastics (Anderson and Lamsal, 2011). However, materials from individual biopolymers (starch or zein alone) mostly have inferior properties compared to synthetic polymers. For example, starch films are hydrophilic and have poor mechanical properties (Argüello-García et al., 2014). Films produced from 100\% zein are also brittle under normal conditions (Soliman et al., 2009). On the other hand, starch and zein have complementary properties, starch having hydrophilic nature and zein is relatively hydrophobic. Also blending starch with zein could reduce the cost compared to zein alone.

Starch-protein blending has shown to improve the material properties of biopolymers. For example, films made from corn starch and casein blend, where both biopolymers are hydrophilic, through intense thermal blending improve the water vapour transmission rate and the tensile strength compared to casein or starch based films alone (Jagannath et al., 2003). However, the blending of starch and zein to produce a stable co-polymer is a challenge due to the relative hydrophobic nature of zein owing to its high contents of non-polar amino acids (Tihminlioglu et al., 2011) and the hydrophilic nature of starch. Corradini et al. (2007) and Habeych et al. (2008) have reported starch-zein incompatibility based on morphological and microscopic evidence, which displayed two separate phases of starch and zein during hot melt blending. To overcome this, Leroy et al. (2012) used an ionic liquid [(1-butyl-3-methylimidazolium chloride 
[BMIM](Cl)] to produce a starch-zein thermoplastic blend by melt processing using a twin screw micro-compounder. However, the safety and availability of these ionic liquids is problematic.

The objective of this research was therefore; to investigate the formation of pre-gelatinized maize starch-zein compatible binary colloidal blends in water at alkaline $\mathrm{pH}(0.1 \mathrm{M} \mathrm{NaOH}$ solution). $\mathrm{NaOH}$ was used because zein is soluble in water at alkaline $\mathrm{pH} \geq 11$ (Shukla and Cheryan, 2001). Alkaline treatment of starch also favours starch dissolution and expansion of the amylose coil due to charge repulsion (Chen and Jane, 1994).

\section{MATERIALS AND METHODS}

\subsection{Materials}

Native starch from white maize was acquired from Tongaat Hulett Starch (Johannesburg, South Africa). The amylose content was about $28.9 \%$, determined according to the method by Imberty et al. (1991). Commercial zein (Z3625) (primarily $\alpha$-zein) was from Sigma-Aldrich (Johannesburg, South Africa). The zein was defatted with n-hexane (1 part zein: 3 parts nhexane, w/v) at ambient temperature. Protein content was $90.3 \%(\mathrm{~N} \times 6.25)$ as is basis, determined by a Dumas nitrogen combustion method, AACC International (2000) Method 4630.

\subsection{Methods}

2.2.1 Preparation of pre-gelatinized (uncomplexed or complexed with stearic acid) maize starch

Pre-gelatinized maize starch was prepared as described by D'Silva et al. (2011), except that $40 \mathrm{~g}$ starch was pasted using a Brabender Viscoamylograph-E (Brabender ${ }^{\circledR} \mathrm{OHG}$, Duisburg, 
Germany) instead of Rapid Visco Analyser. Briefly; stearic acid (1.5\% w/w in relation to starch) was dissolved in ethanol (3:1 ethanol: starch ratio) and mixed with starch before pasting to prepare complexed starch. The uncomplexed starch was suspended in ethanol. The suspension was thoroughly mixed at $50{ }^{\circ} \mathrm{C}$ in shaking water bath for $30 \mathrm{~min}$. The ethanol was evaporated off. The starch $(10 \% \mathrm{w} / \mathrm{v})$ was then wet heat treated for extended time $(120 \mathrm{~min})$ at $90^{\circ} \mathrm{C}$. The hot paste was frozen in liquid nitrogen, then freeze dried and stored at $10{ }^{\circ} \mathrm{C}$ until further use.

2.2.2 Formation of pre-gelatinized maize starch (uncomplexed or complexed with stearic acid) and zein blends

Pre-gelatinized maize starch (uncomplexed or complexed with stearic acid) and zein were dispersed in water (1:1 starch: zein ratio) and in $0.1 \mathrm{M} \mathrm{NaOH}$, starch: zein ratios of 3:1; 1:1 and 1:3 (w/w), respectively to make a total of $5 \%(\mathrm{w} / \mathrm{v})$ dispersion. The dispersions were vigorously mixed at $70{ }^{\circ} \mathrm{C}$ for 5 min using an Ultra Turrax T25 (IKA, Staufen, Germany) at $8000 \mathrm{rpm}$. The samples were cooled to room temperature $\left(22{ }^{\circ} \mathrm{C}\right)$ for $30 \mathrm{~min}$ and immediately analysed as below.

\subsection{Analyses}

\subsubsection{Visual Examination for Blend Stability}

Approximately $18 \mathrm{ml}$ of each blend was transferred into a test tube and held at ambient temperature $\left(22{ }^{\circ} \mathrm{C}\right)$. The blends were visually examined for any separated liquid (blend instability) after 30 min and after 24 h storage and photographs were taken at each observation time. 


\subsubsection{Ambient temperature $\left(22{ }^{\circ} \mathrm{C}\right)$ storage stability of pre-gelatinized maize starch} (uncomplexed or complexed with stearic acid) and zein blends

A sample of each blend (18 g) immediately after preparation was measured into a plastic centrifuge tube and centrifuged at $955 \mathrm{~g}$ for $10 \mathrm{~min}$ at $25^{\circ} \mathrm{C}$. The amount of liquid separated was measured. The remaining part was left at ambient temperature $\left(22^{\circ} \mathrm{C}\right)$ for $24 \mathrm{~h}$ and centrifuged at $955 \mathrm{~g}$ for $10 \mathrm{~min}$ at $25{ }^{\circ} \mathrm{C}$. The amount of liquid separated was measured. This procedure was repeated for 5 days and the blend stability was calculated as:

$$
\% \text { liquid separated }=\frac{\text { weight of liquid separated }}{\text { original weight of blend }} \text { X } 100
$$

2.3.3 Freeze-thaw stability of pre-gelatinized maize starch (uncomplexed or complexed with stearic acid) and zein blends

Each blend (18 g) was measured into a plastic centrifuge tube and centrifuged at $955 \mathrm{~g}$ for 10 min at $25{ }^{\circ} \mathrm{C}$. This was considered as cycle 0 . The separated liquid was weighed and the remaining part was frozen at $-18{ }^{\circ} \mathrm{C}$ for $24 \mathrm{~h}$. It was then thawed out at $30{ }^{\circ} \mathrm{C}$ for $1 \mathrm{~h}$, centrifuged at $955 \mathrm{~g}$, the separated liquid was weighed and the remaining part frozen at $-18{ }^{\circ} \mathrm{C}$. This was repeated for 5 consecutive freeze-thaw cycles and the blend stability was calculated as above.

\subsubsection{Degree of Deamidation}

Degree of deamidation was determined as described by Cabra et al. (2007). Briefly, zein 0.5\% (w/v) was dispersed in water (control), and dissolved in $0.1 \mathrm{M} \mathrm{NaOH}$ and $3 \mathrm{M}$ sulphuric acid (standard) by the same process as the blends above. After incubation for $30 \mathrm{~min}$ at $22{ }^{\circ} \mathrm{C}$, the 
quantity of ammonia released was determined using an Ammonia Enzymatic BioAnalysis Test 106 Kit (Ammonia Assay Kit, Sigma-Aldrich). Degree of deamidation was expressed as the ratio of 107 the amount of released ammonia by deamidation reactions and the total released ammonia when 108 the zein was treated with $3 \mathrm{M}$ sulphuric acid.

\subsubsection{Zeta Potential}

The 5\% dispersions of zein, pre-gelatinized maize starch (uncomplexed or complexed with 111 stearic acid) and starch-zein blends were diluted to $0.5 \%(\mathrm{w} / \mathrm{v})$. The solvents used were water 112 (control) and $0.1 \mathrm{M} \mathrm{NaOH}$. Zeta potential was measured by laser doppler velocimetry and phase 113 analysis light scattering (M3-PALS) technique using a Malvern Zetasizer Nano ZS Model 114 ZEN3600 (Malvern Instruments, Malvern, U.K.).

\subsubsection{Viscometry}

Viscometry was conducted using a Physica MCR 101 Rheometer (Anton Paar, Ostfildern, Germany) using a bob and cup. The blends were centrifuged at $166 g$ to remove the air bubbles and allowed to equilibrate for $10 \mathrm{~min}$ at $25^{\circ} \mathrm{C}$. Shear rate was increased from 0.1 to $100 / \mathrm{s}$ and 119 reduced back from 100 to $0.1 / \mathrm{s}$. The measurements were taken at $25^{\circ} \mathrm{C}$. The experimental data 120 were fitted to the Power Law model:

$\sigma=\mathrm{K}(\dot{\gamma})^{\mathrm{n}}$

Where $\sigma$ is the shear stress $(\mathrm{Pa}), \dot{\gamma}$ is the shear rate $(1 / \mathrm{s}), \mathrm{K}$ is the consistency index $\left(\mathrm{Pa} . \mathrm{s}^{\mathrm{n}}\right)$, and $\mathrm{n}$ is the flow index where $\mathrm{n}=1$ for Newtonian fluid, $\mathrm{n}<1$ for shear thinning and $\mathrm{n}>1$ for shear thickening materials. 


\subsubsection{Confocal laser scanning microscopy}

Safranin O dye (Sigma-Aldrich) $0.002 \%$ of zein content (dry basis) was added to the blends to stain the zein. The dye was solubilised in $0.1 \mathrm{M} \mathrm{NaOH}$ before mixing the starch and zein to ensure homogenous distribution. The samples were degassed and a small amount of each blend sample was placed on a concave microscope slide and covered with cover slip. A Zeiss LSM 510 META Confocal Laser Scanning Microscope (Jena, Germany) at 40x magnification was used. Plane neoflar100x and numerical aperture (N.A) 1.4 were used for the blend images. The pixel time for both tracks 1 and 2 was $12.8 \mu$ s. Picture size was 512 x 512 pixels. The excitation and emission spectra for the Safranin O dye were $488 \mathrm{~nm}$ and $540 \mathrm{~nm}$, respectively.

\subsection{Statistical analysis}

All data was analyzed by one-way analysis of variance (ANOVA). Significant differences among the means were determined by the Tukey (HSD) test. All experiments were repeated at least two times, unless otherwise stated. The independent variables were type of starch (uncomplexed and complexed with stearic acid), and starch: zein ratio (3:1, 1:1 and 1:3, respectively). 


\section{RESULTS AND DISCUSSION}

Pre-gelatinized maize starch (both uncomplexed and complexed with stearic acid) and zein in 0.1 $\mathrm{M} \mathrm{NaOH}$ showed a colloidal suspension with no liquid separated after 30 min and after $24 \mathrm{~h}$ storage (Figure 1A and F). Pre-gelatinized maize starch (both uncomplexed and complexed with stearic acid)-zein blend (1:1 ratio) in water (control) showed liquid separation immediately after preparation (Figure 1B). This is because of the immiscibility of the pre-gelatinized starch and zein (Habeych et al., 2008) mainly due to the hydrophilic nature of starch and relatively hydrophobic nature of zein. Pre-gelatinized maize starch (both uncomplexed and complexed with stearic acid)-zein blends at all starch: zein ratios in $0.1 \mathrm{M} \mathrm{NaOH}$ were found to form a colloidal blend with no liquid separation after 30 min (Figure 1C, D \& E - 30 min). However, after 24 h storage at $22{ }^{\circ} \mathrm{C}$ starch (both uncomplexed and complexed with stearic acid)-zein blend at 1:3 ratio in $0.1 \mathrm{M} \mathrm{NaOH}$ showed liquid separation, while the 3:1 and 1:1 starch: zein ratios blend were stable (Figure 1C, D \& E - 24 h). This suggests that compatible pre-gelatinized (uncomplexed or complexed with stearic acid) maize starch-zein binary colloidal blends were formed at starch: zein ratios of 3:1 and 1:1.

During mixing to produce the blends, foam was produced in zein suspension alone and the 1:1 starch (uncomplexed or complexed with stearic acid)-zein blends (Figure 1D \& F - 30 min). The foam volume on top of the starch complexed with stearic acid-zein blend (1:1 ratio) was larger than the foam on top of the uncomplexed starch-zein blend (1:1 ratio) (Figure 1D). This suggests that the starch complexed with stearic acid imparted better foaming capacity compared to uncomplexed starch when blended with zein. 

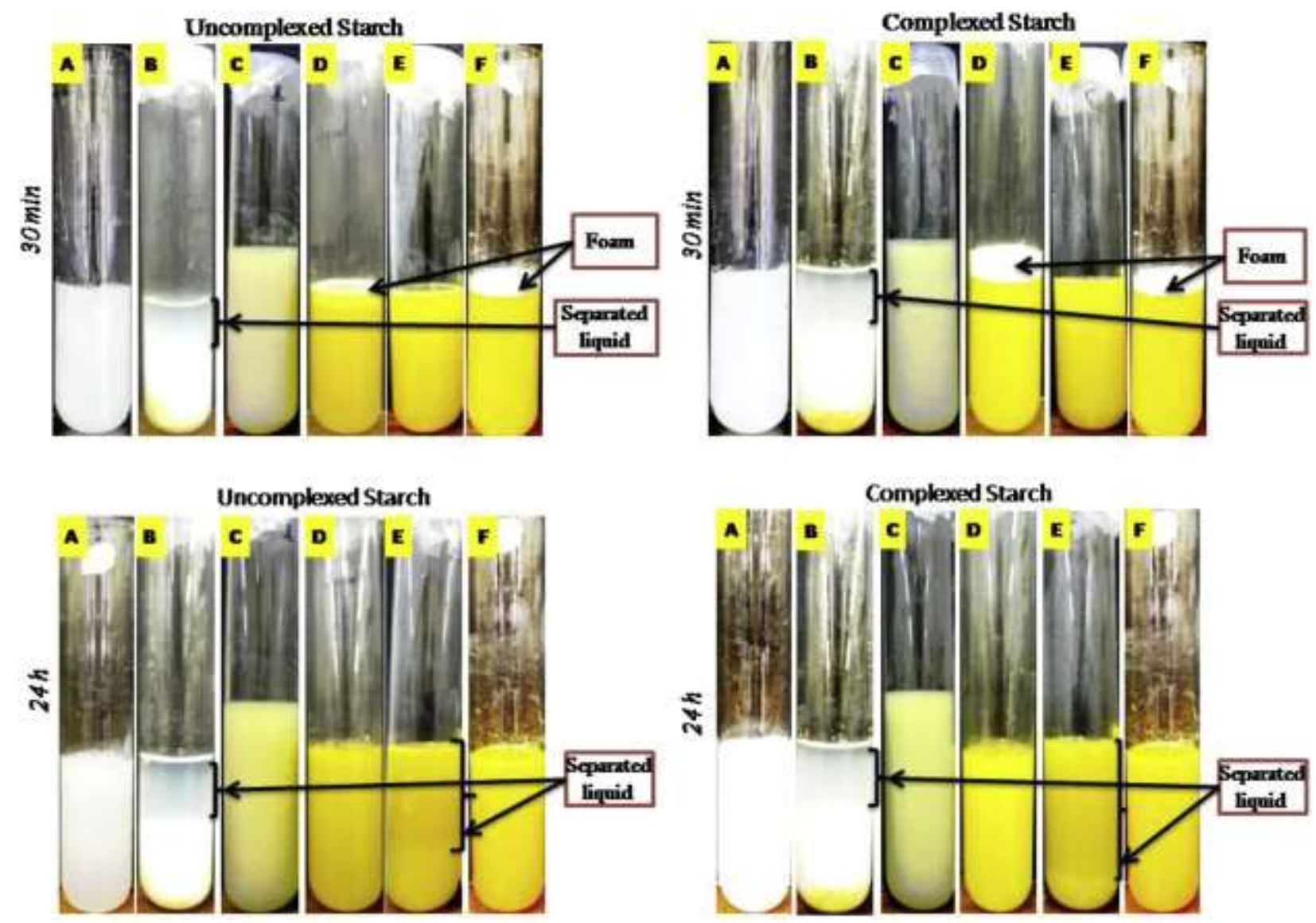

Fig. 1. Images of pre-gelatinized maize starch (uncomplexed and complexed with stearic acid), zein and pregelatinized maize starch (uncomplexed and complexed with stearic acid) -zein colloidal blends in $0.1 \mathrm{M} \mathrm{NaOH}$ at different starch:zein ratios after $30 \mathrm{~min}$ and $24 \mathrm{~h}$ storage at ambient temperature $\left(22^{\circ} \mathrm{C}\right)$. A - Pre-gelatinized maize starch (uncomplexed or complexed with stearic acid), B - starch: zein (1:1) in water, C -starch: zein (3:1), D - starch:zein (1:1), E - starch:zein (1:3) and F - zein. * The difference in volume between the samples was due to difference in foaming. 
The ambient temperature $\left(22{ }^{\circ} \mathrm{C}\right)$ storage and freeze-thaw stability tests of the colloidal blends are presented in Figure 2a and b. Pre-gelatinized maize starch (uncomplexed and complexed with stearic acid) and pre-gelatinized maize starch (uncomplexed and complexed with stearic acid)-zein blends at 3:1 and 1:1 ratios were stable with no liquid separation during the five days storage (Figure 2a). However, both uncomplexed starch and starch complexed with stearic acid-zein blends at 1:3 ratio and zein alone showed instability with $>70 \%$ liquid separated starting from day 1.

Pre-gelatinized maize starch (uncomplexed and complexed with stearic acid) was stable with no liquid separation during the five freeze-thaw cycles (Figure 2b). However, when the starch was blended with zein, only the starch (complexed with stearic acid)-zein blend (3:1 ratio) was relatively stable during the five freeze- thaw cycles with $5 \%$ liquid separated at the $5^{\text {th }}$ cycle. Pregelatinized uncomplexed maize starch-zein at 3:1, 1:1 and 1:3 ratio blends showed instability starting from the $1^{\text {st }}$ cycle with a separated liquid values of $8.1 \%, 27.7 \%$ and $71.5 \%$, respectively. Pre-gelatinized maize starch complexed with stearic acid-zein blends at 1:1 and 1:3 ratios also showed instability starting from the $1^{\text {st }}$ cycle with $29.5 \%$ and $62.7 \%$ separated liquid, respectively.

Repeated freeze-thawing cycles are reported to accelerate starch retrogradation in a paste or gel (Jacobson and BeMiller, 1998). The starch retrogradation resulted in syneresis (liquid separation). This liquid separation occurs mainly due to retrogradation of amylose (Morris, 1990). The relative stability of the 3:1 maize starch complexed with stearic acid-zein blend could be related to the non-gelling behaviour of starch complexed with stearic acid (D'Silva et al., 2011). 
a)

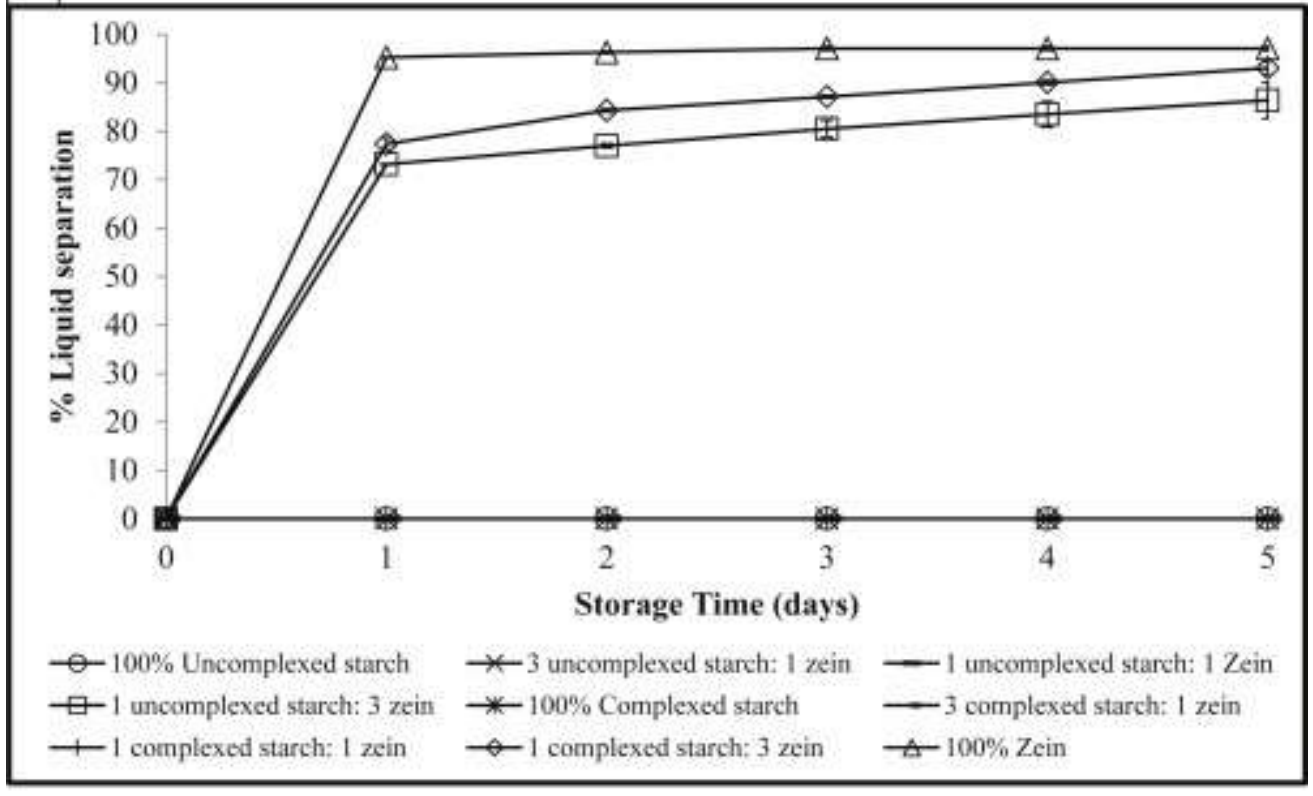

b)

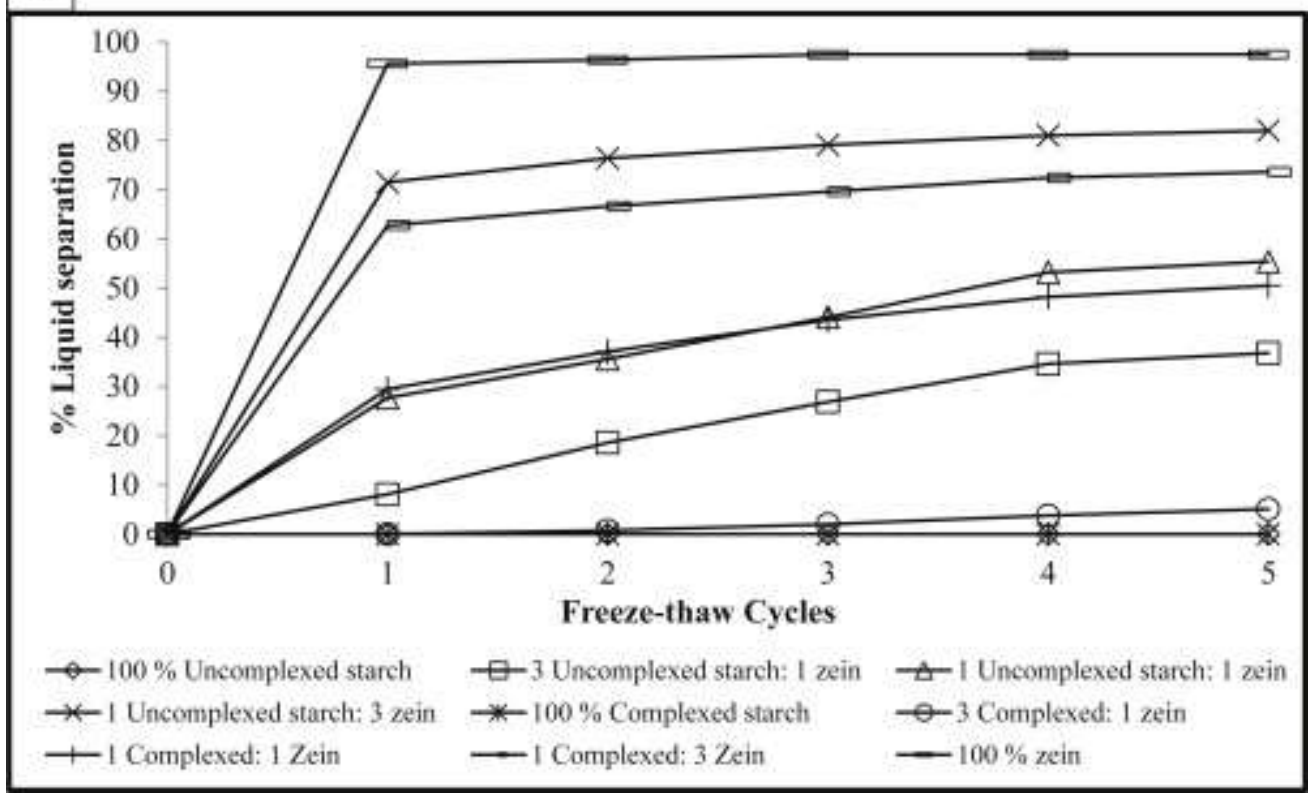

Fig. 2. a) Ambient temperature $\left(22^{\circ} \mathrm{C}\right)$ storage stability and b) freeze-thaw stability of pre-gelatinized maize starch (uncomplexed or complexed with stearic acid), zein and pre-gelatinized maize starch (uncomplexed and complexed with stearic acid) - zein colloidal blends at different starch: zein ratios (3:1, 1:1 and 1:3). Error bars show standard deviations. 
To determine whether the stability of the blends in $0.1 \mathrm{M} \mathrm{NaOH}$ was as a result of deamidation of zein, zein amide content and zeta potential of the zein, starch and blends were measured. Zein treated with $0.1 \mathrm{M} \mathrm{NaOH}$ had a far higher degree of deamidation (77.3\%) compared to zein in water (12.4\%). Cabra et al. (2007) had also found more than 60\% deamidation of $\alpha$-zein when treated with $0.5 \mathrm{M}, 1.0 \mathrm{M}$ and $1.5 \mathrm{M} \mathrm{NaOH}$ in $70 \%$ ethanol incubated at $70^{\circ} \mathrm{C}$ for 30 h. Zhang et al. (2011) also found zein deamidation at alkaline pH (12.5) using $\mathrm{NaOH}$.

The zeta potential values of zein and pre-gelatinized (uncomplexed and complexed with stearic acid) maize starch in $0.1 \mathrm{M} \mathrm{NaOH}$ were significantly more negative than the zeta potential of each biopolymer in water $(\mathrm{p}<0.001)$ (Table 1). Zein, pre-gelatinized (uncomplexed and complexed with stearic acid) maize starch and blends of pre-gelatinized (uncomplexed and complexed with stearic acid) maize starch and zein had a zeta potential values of $\leq-14.5 \mathrm{mV}$. Zeta potential is a measure of charges carried by particles suspended in a liquid (mostly water). Zeta potential values greater than $-15 \mathrm{mV}$ usually can represent the onset of agglomeration (Riddick, 1968). Almost all the blends and the individual biopolymers in $0.1 \mathrm{M} \mathrm{NaOH}$ have a zeta potential value of $\leq-15 \mathrm{mV}$ (more negative) which is below the threshold value of agglomeration. The high degree of deamidation of zein in $0.1 \mathrm{M} \mathrm{NaOH}$ (Table 1) could be the cause of the negative zeta potential value of zein in 0.1 $\mathrm{M} \mathrm{NaOH}$. During deamidation the amide groups changed to hydroxyl groups and convert glutamine residues (most abundant in cereal proteins) to glutamic acid residues. This increases the number of negatively charged carboxyl groups ( $\mathrm{COO}^{-}$) in the peptide chain (Cabra et al., 2007; Kanerva et al., 2011). Zhang et al. (2011) reported a more negative zeta potential of -21 mV at pH 12.5 compared to $-0.94 \mathrm{mV}$ at $\mathrm{pH} 6.5$ for zein. The higher negative zeta potential of pregelatinized maize starch (both uncomplexed (- $16.7 \mathrm{mV}$ ) and complexed with stearic acid (-18.2 $\mathrm{mV})$ ) in $0.1 \mathrm{M} \mathrm{NaOH}$ compared to their zeta 
Table 1. Zeta potential values of zein, pre-gelatinized maize starch (uncomplexed and complexed with stearic acid) in water and in $0.1 \mathrm{M} \mathrm{NaOH}$, and pre-gelatinized maize starch (uncomplexed or complexed with stearic acid)-zein blends in $0.1 \mathrm{M} \mathrm{NaOH}$.

\section{Treatment}

Zein

Uncomplexed maize starch

Complexed maize starch with stearic acid

Zein

Uncomplexed maize starch

Complexed maize starch with stearic acid

Uncomplexed maize starch-zein blend

Uncomplexed maize starch-zein blend

Uncomplexed maize starch-zein blend

Complexed starch with stearic acid-zein blend

Complexed starch with stearic acid-zein blend

Complexed starch with stearic acid-zein blend

\begin{tabular}{|c|c|c|}
\hline $\begin{array}{l}\text { Starch:zein } \\
\text { ratio }\end{array}$ & Solvent & pH $\begin{array}{c}\text { Zeta potential } \\
(\mathrm{mV})\end{array}$ \\
\hline $0: 1$ & Water & $3.6 \quad 43.0 \mathbf{a}( \pm 0.5)$ \\
\hline $1: 0$ & Water & $6.9-3.6 \mathbf{b}( \pm 0.1)$ \\
\hline $1: 0$ & Water & $7.2-8.9 \mathbf{c}( \pm 0.3)$ \\
\hline $0: 1$ & $\begin{array}{l}0.1 \mathrm{M} \\
\mathrm{NaOH}\end{array}$ & $12.2-16.0$ de $( \pm 0.1)$ \\
\hline 1:0 & $\begin{array}{l}0.1 \mathrm{M} \\
\mathrm{NaOH}\end{array}$ & $12.1-16.7$ ef $( \pm 0.2)$ \\
\hline $1: 0$ & $\begin{array}{l}0.1 \mathrm{M} \\
\mathrm{NaOH}\end{array}$ & $12.3-18.2 \operatorname{gh}( \pm 0.1)$ \\
\hline $3: 1$ & $\begin{array}{l}0.1 \mathrm{M} \\
\mathrm{NaOH}\end{array}$ & $12.1-19.1 \mathbf{h}( \pm 1.1)$ \\
\hline $1: 1$ & $\begin{array}{l}0.1 \mathrm{M} \\
\mathrm{NaOH}\end{array}$ & $12.2-17.7$ fgh $( \pm 0.2)$ \\
\hline :3 & $\begin{array}{l}0.1 \mathrm{M} \\
\mathrm{NaOH}\end{array}$ & $12.3-18.6 \mathbf{g h}( \pm 0.9)$ \\
\hline $3: 1$ & $\begin{array}{l}0.1 \mathrm{M} \\
\mathrm{NaOH}\end{array}$ & $12.2-17.5 \mathbf{f g}( \pm 0.8)$ \\
\hline $1: 1$ & $\begin{array}{l}0.1 \mathrm{M} \\
\mathrm{NaOH}\end{array}$ & $12.3-14.5 \mathbf{d}( \pm 0)$ \\
\hline $1: 3$ & $\begin{array}{l}0.1 \mathrm{M} \\
\mathrm{NaOH}\end{array}$ & $12.2-15.9$ de $( \pm 0.1)$ \\
\hline
\end{tabular}

Means followed by different letters are significantly different $(\mathrm{P}<0.0001)$, Tukey (HSD) test. $\mathrm{n}=3$.

Values in parentheses show standard deviation. 
potential value in water (-3.6 and $-8.9 \mathrm{mV}$ ) (Table 2) could be due to an alkalization reaction where the hydroxyl groups of the starch molecules are activated and changed into the more reactive and negatively charged alkoxide form (Starch-O־) (Lawal et al., 2008).

The visco metry and microstructure of the blends were investigated. Apparent viscosity vs. shear rate graph was plotted (Figure 3) and the viscometry data (shear rate vs. shear stress) was fitted 211 to the Power Law model. Table 2 summarizes the Power Law paramenters of the treatments. The 212 viscometry data showed a good fit to the Power Law model as the coefficient of determination $213\left(\mathrm{R}^{2}\right)$ for all the treatments were greater than 0.90 (Table 2). All the treatments except zein alone 214 showed shear thinning behaviour with $\mathrm{n}$ (flow index value) from the Power Law equation to be $<2151$. This shear thinning behaviour can also be seen from the apparent viscosity vs. shear rate 216 graph, where the apparent viscosity decreased as the shear rate increased. Zein showed a 217 Newtonian behaviour, where the $n$ (flow index value) $=1$. The apparent of viscosity vs. shear 218 rate graph of zein was also in agreement to the n-value, where no decrease in apparent viscosity 219 was observed with increase in shear rate. This agrees with research which showed that $\alpha$-zein 2 - $22014 \%(\mathrm{w} / \mathrm{w})$ in aqueous ethanol exhibited Newtonian behaviour (Fu and Weller, 1999).

The blending of zein with pre-gelatinized maize starch reduced the apparent viscosity compared to the pre-gelatinized maize starch (Figure 3). The consistency index (K-value), an indication of shear viscosity (Xie et al., 2009) was also substantially reduced when zein was blended with pregelatinized maize starch compared to the pre-gelatinized maize starch (Table 2). Similarly, Corradini et al. (2007) reported a reduction of starch melt viscosity when blended with zein. The apparent viscosity and K-value of the blends decreased with decreasing the proportion of the starch from 3 Starch: 1 zein to 1 starch: 1 zein and 1 starch: 3 zein. However, the n-value 


\section{Table 2.}

Power law consistency coefficient $(\mathrm{K})$ values $\left(\mathrm{Pa} \cdot \mathrm{s}^{\mathrm{n}}\right)$, flow behaviour index $(\mathrm{n})$ values and $\mathrm{R}^{2}$ values of $5 \%(\mathrm{w} / \mathrm{v})$ pre-gelatinized maize starches (uncomplexed or complexed with stearic acid), zein and blends of pre-gelatinized maize starch (uncomplexed or complexed with stearic acid) and zein at different ratios.

\begin{tabular}{|c|c|c|c|c|}
\hline Treatment & $\begin{array}{l}\text { Starch:Zein } \\
\text { ratio }\end{array}$ & K-value & n-value & $\begin{array}{l}\mathbf{R}^{2}- \\
\text { value }\end{array}$ \\
\hline Uncomplexed maize starch & $1: 0$ & $\begin{array}{l}2.2 \times 10^{1} \mathbf{b} \\
( \pm 0.15)\end{array}$ & $\begin{array}{l}0.42 \mathbf{e} \\
( \pm 0.00)\end{array}$ & 0.99 \\
\hline $\begin{array}{l}\text { Complexed maize starch with } \\
\text { stearic acid }\end{array}$ & $1: 0$ & $\begin{array}{l}3.5 \times 10^{1} \mathbf{a} \\
( \pm 2.07)\end{array}$ & $\begin{array}{l}0.32 \mathbf{e f} \\
( \pm 0.00)\end{array}$ & 0.99 \\
\hline $\begin{array}{l}\text { Uncomplexed maize starch-Zein } \\
\text { blend }\end{array}$ & $3: 1$ & $\begin{array}{l}0.6 \times 10^{1} \mathbf{d} \\
( \pm 0.53)\end{array}$ & $\begin{array}{l}0.40 \mathbf{e} \\
( \pm 0.01)\end{array}$ & 0.99 \\
\hline $\begin{array}{l}\text { Uncomplexed maize starch-Zein } \\
\text { blend }\end{array}$ & $1: 1$ & $\begin{array}{l}4.3 \times 10^{-1} \mathbf{e} \\
( \pm 0.03)\end{array}$ & $\begin{array}{l}0.63 \mathbf{c} \\
( \pm 0.01)\end{array}$ & 0.99 \\
\hline $\begin{array}{l}\text { Uncomplexed maize starch-Zein } \\
\text { blend }\end{array}$ & $1: 3$ & $\begin{array}{l}2.0 \times 10^{-2} \mathbf{e} \\
( \pm 0.00)\end{array}$ & $\begin{array}{l}0.91 \mathbf{b} \\
( \pm 0.02)\end{array}$ & 0.99 \\
\hline $\begin{array}{l}\text { Maize starch complexed with } \\
\text { stearic acid-Zein blend }\end{array}$ & $3: 1$ & $\begin{array}{l}1.1 \times 10^{1} \mathbf{c} \\
( \pm 0.80)\end{array}$ & $\begin{array}{l}0.30 \mathbf{f} \\
( \pm 0.01)\end{array}$ & 0.96 \\
\hline $\begin{array}{l}\text { Maize starch complexed with } \\
\text { stearic acid - Zein blend }\end{array}$ & $1: 1$ & $\begin{array}{l}4.0 \times 10^{-1} \mathbf{e} \\
( \pm 0.01)\end{array}$ & $\begin{array}{l}0.58 \mathbf{d} \\
( \pm 0.01)\end{array}$ & 0.99 \\
\hline $\begin{array}{l}\text { Maize starch complexed with } \\
\text { stearic acid-Zein blend }\end{array}$ & $1: 3$ & $\begin{array}{l}1.0 \times 10^{-2} \mathbf{e} \\
( \pm 0.00)\end{array}$ & $\begin{array}{l}0.99 \mathbf{a b} \\
( \pm 0.01)\end{array}$ & 0.99 \\
\hline Zein & $0: 1$ & $\begin{array}{l}1.0 \times 10^{-3} \mathbf{e} \\
( \pm 0.00)\end{array}$ & $\begin{array}{l}1.00 \mathbf{a} \\
( \pm 0.00)\end{array}$ & 0.97 \\
\hline
\end{tabular}

Means followed by different letters within a block are significantly different $(\mathrm{P}<0.0001)$, Tukey (HSD) test. $\mathrm{n}=3$.

Values in parentheses are standard deviations. 


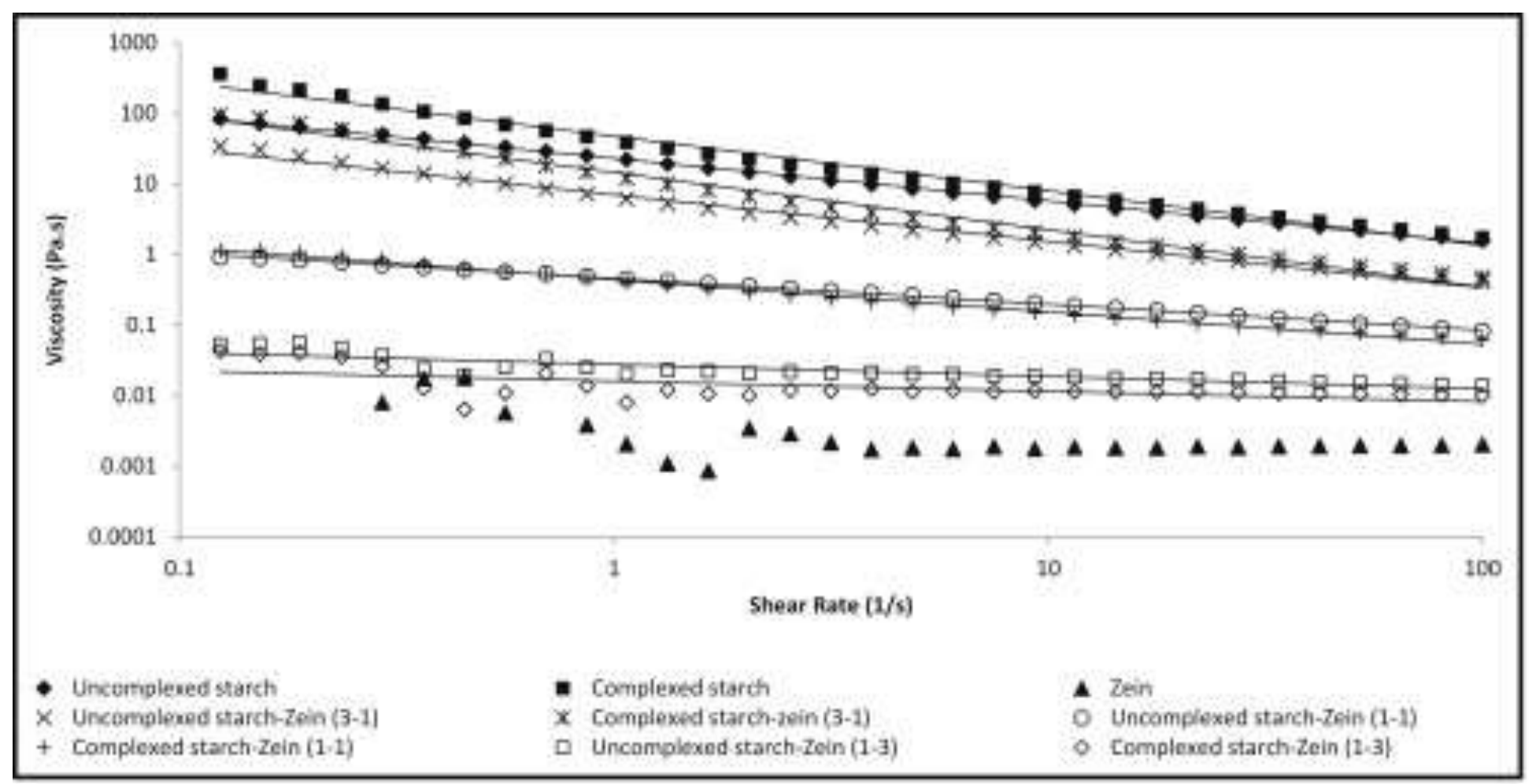

* The viscosity vs, shear rate data of pure zein did not fit to the Power Law trending line.

Fig. 3. Apparent viscosity vs. Shear rate graphs of pre-gelatinized maize starch (uncomplexed and complexed with stearic acid), zein and pre-gelatinized maize starch-zein blends at different starch: zein ratios (3:1, 1:1 and 1:3). *The viscosity vs. shear rate data of pure zein did not fit to the Power Law trending line. 
increased with decrease in starch proportion. The K-value of the 3:1 ratio starch complexed with stearic acid-zein blend was significantly higher $(\mathrm{P}<0.001)$ than the K-value of 3:1 ratio uncomplexed starch-zein blend. The apparent viscosity and K-value of the blends seemed to be related to the stability of the blends. The 3:1 starch-zein blends were found to be more stable and have higher apparent viscosity and K-values compared to the 1:1 and 1:3 starch-zein blends (Figures 2a and b, Figure 3, Table 2).

Confocal laser scanning microscopy was used to investigate the microstructure of the blends (Figure 4). Three different colour domains were observed: black, light yellow and bright yellow. The starch samples were unstained and showed black colour (Figure 4A, B) and the zein sample showed bright yellow and black colour (Figure 4C). Thus, the black colour can be considered to be starch (unstained) and/or solvent, the bright yellow to be zein (stained with safranin O) and the light yellow is presumed to be starch-zein mixed. The arrows indicate these three different areas, starch/solvent, zein or starch-zein mixture. Starch-zein blends with different starch: zein ratios (3:1, 1:1 and 1:3) showed different microstructures. Type of starch (uncomplexed and complexed with stearic acid) also affected microstructure. The 3:1 ratio uncomplexed starch-zein blend showed some aggregated zein (bright yellow coloured), starch and starch-zein mixed (light yellow coloured) (Figure 4D). However, the 3:1 ratio starch complexed with stearic acid-zein blend showed mostly a mixture of starch and zein as indicated by the light yellow colour (Figure 4G). The uncomplexed starch- zein blend (1:1 ratio) showed some zein aggregation (bright yellow), some starch/solvent (dark) and a mixture of starch and zein (light yellow) (Figure 4E). Less zein aggregation was observed in the complexed starch with stearic acid-zein blend (1:1 ratio) (Figure 4H) compared to the uncomplexed starch-zein blend (1:1 ratio). Both the uncomplexed starch-zein blend (1:3 ratio) and the complexed starch with stearic acid-zein blends (1:3 ratio) showed zein aggregat ion (bright yellow) where the one with 

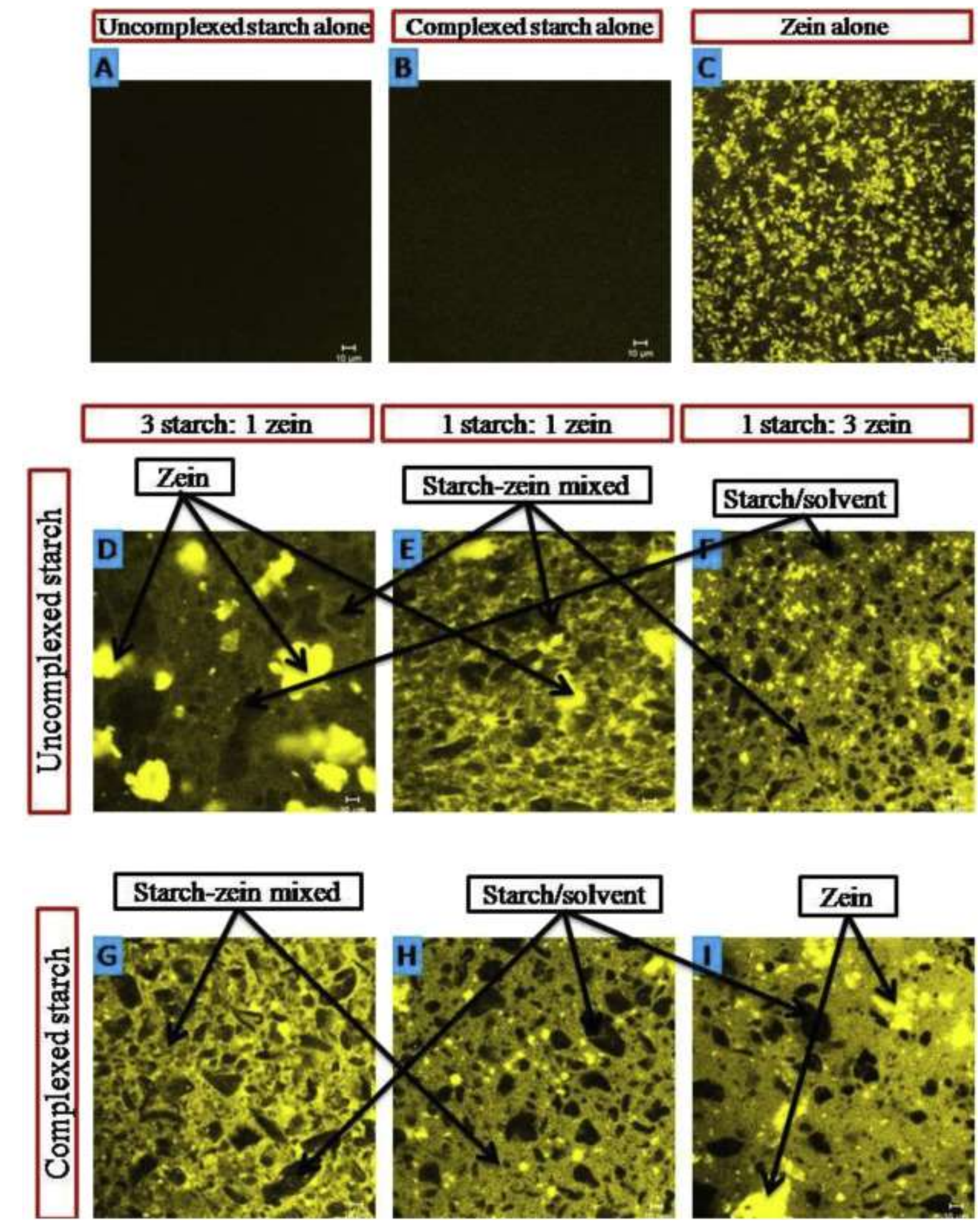

Fig. 4. Confocal laser scanning microscopy of pre-gelatinized maize starch (uncomplexed and complexed with stearic acid), zein and pre-gelatinized maize starch-zein blends. A: uncomplexed maize starch, B: maize starch complexed with stearic acid, C: zein, D: 3:1 uncomplexed starch: zein, E: 1:1 uncomplexed starch: zein, F: 1:3 uncomplexed starch: zein, G: 3: 1 complexed starch with stearic acid: zein, H: 1:1 complexed starch with stearic acid: zein, and I: 1:3 complexed starch with stearic acid: zein. 
complexed starch showing more aggregation (Figure 4F, I). Although proportion of starch was lower in the 1: 1 and 1: 3 starch: zein ratios compared to the 3: 1 ratio, there seems to be more and relatively larger black areas (starch/solvent) in the 1: 1 and 1: 3 ratios. This could further indicate liquid separation in the 1: 1 and 1: 3 ratios of starch: zein blends compared to the 3: 1 starch: zein ratio. The black areas in the pure zein could also indicate liquid separation (instability).

The unique microstructures of the blends are related to the flow properties. Blends where the starch and zein just formed a mixture (light yellow), showed higher apparent viscosity and Kvalue compared to those where the zein aggregated. Colloidal dispersions or emulsions with uniformly distributed particles have higher viscosities than dispersions or emulsions with nonuniform or coarse particle distribution ( $\mathrm{Pal}, 1996)$. The zein aggregation in the 3:1 ratio uncomplexed maize starch-zein blend could be due to the gelling behaviour of the uncomplexed starch. When the starch gels, the zein molecules may not have been able to disperse uniformly throughout the system. The zein aggregates in the 1: 1 and 1: 3 starch: zein ratios could indicate decrease in stability.

To further discuss the findings; alkaline deamidation of zein increased the total negative net charges of the zein molecules as evidenced by the decrease (more negative) of zeta potential (Table 2). This higher net negative charges increases electrostatic repulsion and decreases hydrogen bonding between the zein molecules (Cabra et al., 2007; Kanerva et al., 2011). It is probable that the repulsion between the negatively charged zein molecules will keep them dispersed in the blend system and prevents aggregation. The starch would increase the viscosity of the aqueous phase because of its hydrophilic nature (Glicksman, 1991) and possible also stabilize the dispersed zein molecules. These two mechanisms, the repulsion between the 
negatively charged zein molecules and the stabilizing nature of the starch, could be the main reasons for the formation of compatible blends between pre-gelatinized maize starch and zein under alkaline condition. The sodium ion $\left(\mathrm{Na}^{+}\right)$from $\mathrm{NaOH}$ could also interact with the negatively charged glutamic acid residues forming ionic type interactions to further prevent zein aggregation. The alkalization reaction will cause formation of more reactive and negatively charged starch alkoxide (Starch-O־) (Lawal et al., 2008). This would result in repulsive forces between the starch molecules or would promote ionic interaction with the negatively charged zein molecules, which would further stabilize the system.

The better stability of blends with maize starch complexed with stearic acid compared to blends with uncomplexed maize starch was probably due to the lower retrogradation and syneresis of the starches complexed with stearic acid compared to the uncomplexed starches (D'Silva et al., 2011). Starch complexed with stearic acid is non-gelling as it does not form junction zones (D’Silva et al., 2011). The amylose-lipid complexes are of nanoscale size (Lalush et al., 2005) and could act as nanofillers. Uniform dispersion of nanoparticles leads to a very large matrix/filler interfacial area, and can decrease the molecular mobility and the relaxation behavior, and consequently improves the material properties (Azeredo, 2009).

\section{CONCLUSIONS}

Compatible binary colloidal blends can be produced between pre-gelatinized (uncomplexed and complexed with stearic acid) maize starches and commercial zein using $0.1 \mathrm{M} \mathrm{NaOH}$. The stability of these bipolymeric blends depend on the starch: zein ratio and type of starch (uncomplexed or complexed with stearic acid). A 3:1 starch: zein ratio produces the most stable binary colloidal blend. Blends with maize starch complexed with stearic acid have better stability 
than those using uncomplexed maize starch. The process of producing the compatible pregelatinized maize starch-zein colloidal blends is simple and straight forward. The potential of these bipolymeric blends to form biodegradable coatings and films need to be investigated. 


\section{ACKNOWLEDGMENT}

W.H.T. acknowledges the Institute for Food, Nutrition and Well-being (IFNuW) of the University of Pretoria for financial support and the South African National Research Foundation (NRF) for research funding.

Mr. Alan Hall for help with the confocal laser scanning microscopy. 


\section{REFERENCES}

American Association of Cereal Chemists (AACC International), 2000. Crude proteincombustion. Standard Method 46-30. Approved Methods of the AACC (10 $0^{\text {th }}$ ed.). The Association: St Paul, MN.

Anderson, T. J.; Lamsal, B. P., 2011. Zein extraction from corn, corn products, and coproducts and modifications for various applications: a review. Cereal Chemistry 88, 159173.

Argüello-García, E.; Solorza-Feria, J.; Rendón-Villalobos, J. R.; Rodríguez-González, F.; Jiménez-Pérez, A.; Flores-Huicochea, E., 2014. Properties of edible films based on oxidized starch and zein. International Journal of Polymer Science Article ID 292404, 1-9.

Avalle, N., 1998. Cosmetic powders coated with natural ingredients. Patent EP, 882443.

Azeredo, H. M. C., 2009. Nanocomposites for food packaging applications. Food Research International 42, $1240-1253$.

Carba, V.; Arreguin, R.; Vazquez-Duhalt, R.; Farres, A., 2007. Effect of alkaline deamidation on the structure, surface hydrophobicity, and emulsifying properties of the Z19 $\alpha$-zein. Journal of Agricultural and Food Chemistry 55, 439-445.

Chen, J.; Jane, J., 1994. Properties of granular cold-water-soluble starches prepared by alcoholic-alkaline treatments. Cereal Chemistry 71, 623-626.

Corradini, E.; de Carvalho, A. J. F.; Curvelo, A. A. S.; Agnelli, J. A. M.; Mattoso, L. H. C., 2007. Preparation and characterization of thermoplastic starch/zein blends. Materials Research 10, 227-231. 
D’Silva, T. V.; Taylor, J. R. N.; Emmambux, M. N., 2011. Enhancement of pasting properties of teff and maize starches through wet-heat processing with added stearic acid. Journal of Cereal Science 53, 192-197.

Fu, D.; Weller, C. L., 1999. Rheology of zein solutions in aqueous ethanol. Journal of Agricultural and Food Chemistry 47, 2103-2108.

Glicksman, M., 1991. Hydrocolloids and the search for the "oily grail”. Food Technology 45 (10), 94-103.

Habeych, E.; Dekkers, B.; van der Goot, A. J.; Boom, R., 2008. Starch-zein blends formed by shear flow. Chemical Engineering Science 63, 5229 - 5238.

Imberty, A.; Buléon, A.; Tran, V.; Péerez, S., 1991. Recent advances in knowledge of starch structure. Starch/Stärke 43, 375-384.

Jacobson, M. R.; BeMiller, J. N., 1998. Method for determining of the rate and extent of accelerated starch retrogradation. Cereal Chemistry 75, 22-29.

Jagannath, J. H.; Nanjappa, C.; Das Gupta, D. K.; Bawa, A. S., 2003. Mechanical and barrier properties of edible starch-protein-based films. Journal of Applied Polymer Science 88, 6471.

Kanerva, P.; Brinck, O.; Sontag-Strohm, T.; Salovaara, H.; Loponen, J., 2011. Deamidation of gluten proteins and peptides decreases the antibody affinity in gluten analysis assays. Journal of Cereal Science 53, 335-339.

Kaur, L.; Singh, J.; Liu, Q., 2007. Starch - A potential biomaterial for biomedical applications. In: Mozafari, M. R. (Ed.), Nanomaterials and nanosystems for biomedical applications. Springer: Dordrecht, the Netherlands, pp. 83-98. 
Lalush, I.; Bar, H.; Zakaria, I.; Eichler, S.; Shimoni E., 2005. Utilization of amylose-lipid complexes as molecular nanocapsules for conjugated linoleic acid. Biomacromolecules 6, $121-130$.

Lawal, O. S.; Lechner, M. D.; Kulicke, W. M., 2008. The synthesis conditions, characterizations and thermal degradation studies of an etherified starch from an unconventional source. Polymer Degradation and Stability 93, 1520-1528.

Leroy, E.; Jacquet, P.; Coativy, G.; Reguerre, A. L.; Lourdin, D., 2012. Compatibilization of starch-zein melt processed blends by an ionic liquid used as plasticizer. Carbohydrate Polymers 89, 955-963.

Mathiowitz, E.; Bernstein, H.; Morrel, E.; Schwaller, K., 1991. Method for producing protein microspheres. Patent WO 91/06286.

Morris, V.J., 1990. Starch gelation and retrogradation. Trends in Food Science and Technology 7, 2-6.

Pal, R., 1996. Effect of droplet size on the rheology of emulsions. American Institute of Chemical Engineers Journal 42, 3181-3190.

Riddick, T. M., 1968. Control of colloid stability through zeta potential. New York, p 372.

Shukla, R.; Cheryan, M., 2001. Zein: The industrial protein from corn. Industrial Crops and Products 13, 171-192.

Soliman, E. A.; Eldin, M. S. M.; Furuta, M., 2009. Biodegradable zein-based films: influence of $\gamma$-irradiation on structural and functional properties. Journal of Agricultural and Food Chemistry 57, 2529-2535. 
Tihminlioglu, F.; Atik, I. D.; Özen, B., 2011. Effect of corn-zein coating on the mechanical properties of polypropylene packaging films. Journal of Applied Polymer Science 119, 235241.

Weber, C. J.; Haugaard, V.; Festersen, R.; Bertelsen, G., 2002. Production and applications of biobased packaging materials for the food industry. Food Additives and Contaminants 19, 172-177.

Xie, F.; Yu, L.; Su, B.; Liu, P.; Wang, J.; Liu, H.; Chen, L., 2009. Rheological properties of starches with different amylose/amylopectin ratios. Journal of Cereal Science 49, 371-377.

Zhang, B.; Luo, Y.; Wang, Q., 2011. Effect of acid and base treatments on structural, rheological, and antioxidant properties of $\alpha$-zein. Food Chemistry 124, 210-220. 